\title{
AGREGAÇÃO DE UM NITOSSOLO VERMELHO DISTROFÉRRICO SOB SISTEMAS DE PLANTIO DIRETO, PREPARO CONVENCIONAL E MATA NATIVA
}

\author{
RENATO L. DE ASSIS ${ }^{1}$, KLÉBER P. LANÇAS ${ }^{2}$
}

RESUMO: O presente estudo teve como objetivo avaliar o efeito do tempo de adoção do sistema plantio direto, comparativamente com área de mata nativa e preparo convencional, utilizando a distribuição de agregados do solo em um Nitossolo Vermelho distroférrico. Os tratamentos foram: mata nativa (MN), preparo convencional (PC), plantio direto com um ano (PD1), plantio direto com quatro anos (PD4), plantio direto com cinco anos (PD5) e plantio direto com 12 anos (PD12). Amostras de agregados foram coletadas aleatoriamente dentro de cada tratamento, nas profundidades de 0-5 e 10-15 cm. Após o peneiramento dos agregados em água, esses foram separados nas classes de agregados de $>2 \mathrm{~mm} ;<2 \mathrm{~mm} ; 2-1 \mathrm{~mm}$ e $<1 \mathrm{~mm}$. O tempo de adoção no sistema plantio direto favoreceu a agregação do solo. $\mathrm{O}$ diâmetro médio ponderado (DMP) dos agregados do solo e a percentagem de agregados maiores do que $2 \mathrm{~mm}$ foram crescentes com o tempo de adoção no sistema plantio direto, na profundidade de $0-5 \mathrm{~cm}$. A MN e o PD12 apresentaram maiores DMPs na camada de $0-5 \mathrm{~cm}$. O PC apresentou maior percentual de agregados menores do que $1 \mathrm{~mm}$.

PALAVRAS-CHAVE: tempo de adoção, sistemas de manejo, diâmetro médio geométrico.

\section{AGGREGATION IN A DISTROFERRIC RED NITOSOL UNDER NO-TILL, CONVENTIONAL TILLAGE, AND NATIVE FOREST SYSTEMS}

\begin{abstract}
This study aimed to evaluate the effect of time since the adoption of the no-till system, in comparison with a native forest area and a conventional tillage area, using the distribution of soil aggregates in a Distroferric Red Nitosol. Treatments were as follows: native forest (NF), conventional tillage (CT), no-till for one year (NT1), no-till for four years (NT4), notill for five years (NT5), and no-till for 12 years (NT12). Aggregate samples were collected randomly within each treatment at depths of 0-5 and 10-15 cm. After sifting the aggregates in water they were separated into the following aggregate classes $>2 \mathrm{~mm} ;<2 \mathrm{~mm} ; 2-1 \mathrm{~mm}$, and $<1 \mathrm{~mm}$. The adoption time in the no-till system favored soil aggregation. The mean weighted diameter (MWD) of the soil aggregates and the percentage of aggregates greater than $2 \mathrm{~mm}$ increased with adoption time in the no-till system at the $0-5 \mathrm{~cm}$ depth. The NF and NT12 treatments had higher MWD values in the $0-5 \mathrm{~cm}$ layer. CT had the highest percentage of aggregates smaller than $1 \mathrm{~mm}$.
\end{abstract}

KEYWORDS: adoption time, management systems, geometric mean diameter.

\section{INTRODUÇÃO}

Nas últimas três décadas, houve aumento da intensidade de uso do solo e da mecanização, principalmente com as operações de aração e gradagem, com consequente degradação da estrutura original do solo. A ação dos elementos ativos dos equipamentos de preparo de solo causa modificações, seja pulverizando os horizontes superficiais, seja promovendo a compactação mecânica dos horizontes subsuperficiais (pé de grade/pé de arado). A modernização da agricultura e a utilização mais intensa de máquinas agrícolas provocaram mudanças nos atributos físicos do solo, principalmente na sua estrutura.

\footnotetext{
${ }^{1}$ Professor da Faculdade de Agronomia, FESURV, Universidade de Rio Verde, Caixa Postal 104, Rio Verde - GO, assis@ fesurv.br

${ }^{2}$ Professor do Departamento de Engenharia Rural, FCA/UNESP, Botucatu - SP, kplancas@ @ca.unesp.br

Recebido pelo Conselho Editorial em: 29-3-2008

Aprovado pelo Conselho Editorial em: 1ํ-12-2009

Eng. Agríc., Jaboticabal, v.30, n.1, p.58-66, jan./fev. 2010
} 
A influência da matéria orgânica na agregação do solo ocorre à medida que se adiciona material orgânico ao solo, intensificando a atividade microbiana, resultando na produção de exsudados que desempenham função na formação e na estabilização (agentes cimentantes) dos agregados.

Os efeitos do plantio direto na agregação do solo, pela eliminação das operações de preparo, resultam menor quebra mecânica dos agregados e a manutenção de cobertura por resíduos vegetais, protegendo do impacto direto das gotas de chuva, condições bem diferentes das encontradas no sistema convencional (BERTONI \& LOMBARDI NETO, 1990).

O maior efeito agregante no sistema plantio direto, em comparação ao sistema convencional na camada superficial, foi relatado em diversos trabalhos: CARPENEDO \& MIELNICZUK (1990); DA ROS et al. (1996); BEUTLER et al. (2001); OLIVEIRA (2002); LACERDA et al. (2005); WENDLING et al. (2005). Inúmeros trabalhos relatam a ação das raízes das plantas na formação e estabilização dos agregados do solo (TISDALL \& OADES, 1979; CALONEGO \& ROSOLEM, 2008; SALTON et al., 2008). CUNHA et al. (2007) observaram que a associação de soja com a braquiária contribuiu para a estabilidade dos agregados. CALONEGO \& ROSOLEM (2008) observaram que a estabilidade dos agregados foi maior na camada de 0 a $0,05 \mathrm{~m}$, influenciada pela rotação de culturas (cultivo de triticale e girassol no outono-inverno, associados ao cultivo do milheto, sorgo forrageiro e Crotalária juncea como plantas de cobertura, antecedendo o cultivo da soja).

Avaliando o efeito do tempo de adoção no sistema plantio direto, DA ROS et al. (1996) observaram maiores percentagens de agregados na classe de maior diâmetro $(>2,00 \mathrm{~mm})$ com o tempo de adoção em áreas de um, seis e nove anos, com valores de 20,3\%, 58,72\% e 69,51\%, respectivamente.

Em plantio direto, ocorre aumento do diâmetro médio ponderado (DMP) dos agregados do solo, sendo esse aumento mais acentuado nos primeiros anos de instalação do sistema (CAMPOS et al., 1995). LACERDA et al. (2005) observaram que o DMP foi menor para o preparo convencional do solo em relação ao sistema de plantio direto com 12 anos. CALEGARI et al. (2006) observaram que o preparo convencional contribui para a diminuição dos teores de carbono orgânico do solo e menores valores do DMP, e menor percentagem de agregados $>2,00 \mathrm{~mm}$, enquanto maior agregação e aumento do teor de carbono orgânico foram observados no sistema plantio direto.

Este trabalho teve por objetivo avaliar o efeito do tempo de adoção do sistema plantio direto, comparativamente com área de mata nativa e preparo convencional, utilizando a distribuição de agregados do solo.

\section{MATERIAL E MÉTODOS}

O estudo foi conduzido em um Nitossolo Vermelho distroférrico, relevo ondulado, textura muito argilosa, localizado nas áreas de produção experimental da Fazenda Lageado, no Câmpus da UNESP, Botucatu - SP, sob mata nativa (MN), preparo convencional (PC), plantio direto com um ano (PD1), plantio direto com quatro anos (PD4), plantio direto com cinco anos (PD5) e plantio direto com 12 anos (PD12).

A condição de MN apresenta árvores de grande porte mantidas há mais de 40 anos sem cultivo ou qualquer outro tipo de atividade antrópica. No presente estudo, foi conduzida como área-testemunha.

A área de PC foi cultivada com milho no verão, desde 1983, utilizando a grade aradora e a grade niveladora para o preparo do solo. No ano de 2000, a área foi cultivada no inverno com o triticale (Triticum turgidocereale) e nos anos anteriores foi deixada em pousio.

A área com o PD1 corresponde à área de produção comercial da fazenda. Nas últimas duas safras, foi cultivada com soja e anteriormente com milho. 
A área com o PD4, na safra de 1998/1999, foi cultivada com milho no verão e na safrinha em pousio. Na safra de 1999/2000, cultivou-se a soja no verão e o milheto no inverno. Na safra de 2000/2001, cultivou-se o milho no verão e o triticale como cultura de inverno. No verão de 2001 foi plantado o milho como cultura de verão.

A área com PD5 foi cultivada na safra de verão, 1996/1997, com o milho no verão, e no inverno, a aveia-preta. Na safra seguinte, 1997/1998, a safra de verão também foi o milho e, no inverno, mantida apenas a condução da vegetação espontânea. Na safra de 1998/1999, cultivou-se a soja no verão, e no inverno, o triticale. Nas safras de 1999/2000 e 2000/2001, novamente a soja no verão, e a aveia no inverno.

Na área com o PD12, de 1989 a 1998, cultivou-se a soja como cultura de verão. De 1989 a 1994, o trigo como cultura de inverno; de 1995 a 1996 o tremoço-azul (Lupinus angustifolius); 1997 o triticale; 1998 a aveia-preta (Avena strigosa); 1999 e 2000 o triticale. De 1999 a 2000, a área ficou em pousio no período de verão, apenas com o manejo da vegetação espontânea com a aplicação de herbicidas. No inverno, foi utilizada a aveia-preta. Na safra de 2001/2002, foi cultivada com soja como cultura de verão.

Amostras foram coletadas aleatoriamente dentro de cada tratamento, nas profundidades 0-5 e 10-15 cm. A estabilidade de agregados foi medida pelo método descrito por KEMPER \& CHEPIL (1965), usando agregados com tamanho entre 4,76 e 7,96 mm, que permaneceram em repouso por 10 minutos após água ter sido aspergida sobre eles, antes de iniciar o tamisamento, para permitir umedecimento lento. $\mathrm{O}$ método utiliza o peneiramento dos agregados em água com movimento de oscilação vertical, durante 20 minutos, por meio de peneiras com diâmetro de malha $2 ; 1 ; 0,5 ; 0,25$ e $0,10 \mathrm{~mm}$, separando agregados nas seguintes classes: $>2 \mathrm{~mm} ;<2 \mathrm{~mm} ; 2-1 \mathrm{~mm}$ e $<1 \mathrm{~mm}$. Após determinações das percentagens retidas em cada peneira, calculou-se o diâmetro médio ponderado dos agregados do solo (DMP), conforme KEMPER \& CHEPIL (1965). O carbono orgânico (CO) foi determinado de acordo com metodologia da EMBRAPA (1997).

Os dados experimentais foram analisados de acordo com um delineamento inteiramente casualizado, com nove repetições. Os resultados da distribuição de agregados do solo, DMP e carbono orgânico foram submetidos à análise de variância e teste de Tukey, a 5\% de probabilidade para a comparação de médias, pelo programa SAS (Statistical Analysis System - versão 6.10 (SAS, 1995). As análises de regressão foram realizadas utilizando-se do software Sigma Plot 4.0 (Jandel Scientific).

\section{RESULTADOS E DISCUSSÃO}

A análise de variância mostrou efeitos significativos dos tratamentos (sistemas de manejo e tempo de adoção no sistema plantio direto) e profundidades sobre o DMP, e as diferentes classes de agregados e o carbono orgânico e a interação desses com a profundidade (Tabela 1).

$\mathrm{O}$ teor de carbono orgânico foi maior no tratamento $\mathrm{MN}$ em relação aos sistemas de cultivo estudados (Tabela 2). Isso se deve ao acúmulo de restos vegetais na superfície por um longo período de tempo, não ocorrendo variações nos conteúdos de carbono no tempo em razão da igualdade das quantidades adicionadas e perdidas (BAYER \& MIELNICZUK, 1999). As diferenças nos teores de carbono orgânico entre o PC e o PD5, na profundidade de $0-5 \mathrm{~cm}$, e a diferenciação entre as profundidades, a partir do PD4, estão relacionadas ao retorno dos resíduos culturais associado ao não revolvimento do solo e maior estabilização do sistema.

No presente estudo, o tratamento MN apresentou a maior percentagem de agregados estáveis em água nas classes de maior diâmetro $(>2 \mathrm{~mm})$, com valores acima de $90 \% \mathrm{em}$ ambas as profundidades (Tabela 2). 
TABELA 1. Análise de variância do diâmetro médio ponderado dos agregados do solo (DMP), das diferentes classes de agregados $(>2 \mathrm{~mm},<2 \mathrm{~mm}, 2-1 \mathrm{~mm}$ e $<1 \mathrm{~mm})$ e de carbono orgânico $(\mathrm{CO})$ do Nitossolo Vermelho distroférrico, para os diferentes sistemas de manejo e tempo de adoção do sistema plantio direto. Analysis of variance for mean weighted diameter of soil aggregates (MWD), from different aggregate classes ( $>2$ $\mathrm{mm},<2 \mathrm{~mm}, 2-1 \mathrm{~mm}$, and $<1 \mathrm{~mm}$ ), and organic carbon $(\mathrm{OC})$ in a Distroferric Red Nitosol under different management systems and adoption times of a no-till system.

\begin{tabular}{ccccccc}
\hline \multicolumn{7}{c}{ Causas de Variação } \\
\hline Fontes de Variação & DMP & $>2 \mathrm{~mm}$ & $<2 \mathrm{~mm}$ & $2-1 \mathrm{~mm}$ & $<1 \mathrm{~mm}$ & $\mathrm{CO}$ \\
\hline Tratamento & $* *$ & $* *$ & $* *$ & $* *$ & $* *$ & $* *$ \\
Profundidade & $* *$ & $* *$ & $* *$ & $* *$ & $* *$ & $* *$ \\
Trat. * Prof. & $* *$ & $* *$ & $* *$ & $* *$ & $* *$ & $* *$ \\
\hline C.V. $(\%)$ & 9,61 & 14,18 & 17,52 & 20,31 & 25,98 & 11,17 \\
\hline
\end{tabular}

** Significativo a $1 \%$.

O DMP da área de MN foi de 4,91 e 4,70 mm, para as profundidades de 0-5 e 10-15 cm, respectivamente (Tabela 2). Essa maior agregação no tratamento $\mathrm{MN}$ é resultante do grande acúmulo de matéria orgânica ao longo dos anos, em virtude da não ação antrópica por mais de 40 anos, influenciando fortemente na agregação do solo, relato também observado por BAYER \& MIELNICZUK (1999), em solos sob vegetação natural. A matéria orgânica é responsável por estabilizar os agregados do solo devido a sua maior área superficial e capacidade de troca de íons, possibilitando maior número de ligações eletrostáticas entre as partículas do solo (ANGERS, 1992). LACERDA et al. (2005) observaram que o DMP foi maior na área de mata nativa em relação ao preparo convencional do solo. Dados que corroboram os do presente estudo.

TABELA 2. Valores do diâmetro médio geométrico (DMP), agregados $>2 \mathrm{~mm},<2 \mathrm{~mm}$, entre 2-1 mm e $<1 \mathrm{~mm}$ e carbono orgânico (CO) para os diferentes sistemas de manejo, profundidades e tempo de adoção no sistema plantio direto. Mean geometric diameter values (MWD) for aggregates $>2 \mathrm{~mm},<2 \mathrm{~mm}$, between 2-1 $\mathrm{mm}$, and $<1$ $\mathrm{mm}$, and organic carbon (OC) under different management systems, soil depths, and adoption times of a no-till system.

\begin{tabular}{|c|c|c|c|c|c|c|c|}
\hline Tratamento & $\begin{array}{c}\text { Profund. } \\
\mathrm{cm}\end{array}$ & $\begin{array}{l}\text { DMP } \\
\mathrm{mm}\end{array}$ & $>2 \mathrm{~mm}$ & $<2 \mathrm{~mm}$ & $2-1 \mathrm{~mm}$ & $<1 \mathrm{~mm}$ & $\begin{array}{c}\mathrm{CO} \\
\mathrm{g} \mathrm{kg}^{-1}\end{array}$ \\
\hline \multirow{2}{*}{$\mathrm{MN}$} & $0-5$ & $4,91 \mathrm{Aa}$ & $98,63 \mathrm{Aa}$ & $1,37 \mathrm{~Eb}$ & $0,42 \mathrm{~Eb}$ & $0,95 \mathrm{Db}$ & $61,0 \mathrm{Aa}$ \\
\hline & $10-15$ & $4,70 \mathrm{Aa}$ & $93,54 \mathrm{Ab}$ & $6,46 \mathrm{Ea}$ & $2,81 \mathrm{Da}$ & $3,65 \mathrm{Da}$ & $30,9 \mathrm{Ab}$ \\
\hline \multirow[b]{2}{*}{ PC } & $0-5$ & $1,66 \mathrm{Da}$ & $22,77 \mathrm{Ea}$ & $77,23 \mathrm{Aa}$ & $17,85 \mathrm{Ba}$ & $59,38 \mathrm{Aa}$ & $20,5 \mathrm{Da}$ \\
\hline & $10-15$ & $1,89 \mathrm{Da}$ & $27,56 \mathrm{Ea}$ & $72,44 \mathrm{Aa}$ & $19,19 \mathrm{BCa}$ & $53,25 \mathrm{Aa}$ & $21,7 \mathrm{Ba}$ \\
\hline \multirow[b]{2}{*}{ PD1 } & $0-5$ & $2,50 \mathrm{Cb}$ & $37,90 \mathrm{Db}$ & $62,10 \mathrm{Ba}$ & $21,84 \mathrm{Aa}$ & $40,26 \mathrm{Ba}$ & $22,7 \mathrm{CDa}$ \\
\hline & $10-15$ & $3,11 \mathrm{Ba}$ & $54,96 \mathrm{Ba}$ & $45,04 \mathrm{Db}$ & $16,58 \mathrm{Cb}$ & $28,46 \mathrm{Cb}$ & $21,8 \mathrm{Ba}$ \\
\hline \multirow[b]{2}{*}{ PD4 } & $0-5$ & $2,57 \mathrm{Ca}$ & $42,87 \mathrm{Da}$ & $57,13 \mathrm{Bb}$ & $18,97 \mathrm{Bb}$ & $38,16 \mathrm{Ba}$ & $23,1 \mathrm{CDa}$ \\
\hline & $10-15$ & $2,25 \mathrm{CDa}$ & $32,54 \mathrm{DEb}$ & $67,46 \mathrm{ABa}$ & $26,15 \mathrm{Aa}$ & $41,31 \mathrm{Ba}$ & $19,8 \mathrm{BCb}$ \\
\hline \multirow{2}{*}{ PD5 } & $0-5$ & $3,79 \mathrm{Ba}$ & $65,29 \mathrm{Ca}$ & $34,71 \mathrm{Cb}$ & $13,22 \mathrm{Cb}$ & $21,49 \mathrm{Cb}$ & $28,0 \mathrm{Ba}$ \\
\hline & $10-15$ & $2,91 \mathrm{BCb}$ & $48,91 \mathrm{BCb}$ & $51,09 \mathrm{CD}$ & $22,26 \mathrm{ABa}$ & $28,83 \mathrm{Ca}$ & $21,2 \mathrm{Bb}$ \\
\hline \multirow{2}{*}{ PD12 } & $0-5$ & $4,50 \mathrm{ABa}$ & $88,99 \mathrm{Ba}$ & $11,01 \mathrm{Db}$ & $3,80 \mathrm{Db}$ & $7,21 \mathrm{CDb}$ & $25,0 \mathrm{BCa}$ \\
\hline & $10-15$ & $2,53 \mathrm{BCDb}$ & $40,75 \mathrm{CDb}$ & $59,25 \mathrm{BC}$ & $21,54 \mathrm{ABCa}$ & $37,71 \mathrm{BCa}$ & $16,7 \mathrm{Cb}$ \\
\hline
\end{tabular}

MN - Mata Nativa; PC - Preparo Convencional; PD1 - Plantio Direto com um ano; PD4 - Plantio Direto com quatro anos; PD5 - Plantio Direto com cinco anos; PD12 - Plantio Direto com 12 anos. Letras maiúsculas na coluna comparam diferenças entre os tratamentos para cada profundidade de manejo, e letras minúsculas na coluna comparam diferenças entre as duas profundidades de cada tratamento, a 5\% de probabilidade, pelo teste de Tukey. 
Na profundidade de 0-5 cm, o DMP teve aumento da seguinte ordem: PD1 (51\%), PD4 (55\%), PD5 (128\%), PD12 (171\%) e MN (196\%) em relação ao preparo convencional.

A maior estabilidade de agregados no PD12 e no PD5, na profundidade de 0-5 cm, em relação aos demais anos sob plantio direto, foi verificada por meio do DMP (Tabela 2). Isso pode ser explicado pelas práticas de manejo utilizadas nas áreas: presença de diferentes culturas em safrinha (trigo e aveia-preta) e pelo histórico cultural da área no verão (soja), que tem significativa influência sobre a agregação, quando considerados longos períodos de tempo (HARRIS et al., 1966; SALTON et al., 2008). No presente estudo, a distribuição dos agregados do solo sob PD12 foi a que mais se aproximou da apresentada pelo solo sob mata.

A decomposição lenta e gradual dos resíduos culturais associados ao não revolvimento do solo libera compostos orgânicos que estimulam a formação e a estabilidade de agregados (TISDALL \& OADES, 1982), proporcionando proteção física para a matéria orgânica que atua como elemento de ligação entre os agregados menores para a formação dos agregados maiores.

O efeito do maior DMP na profundidade de $10-15 \mathrm{~cm}$ no PD1, em relação à profundidade de 0-5 cm, deve-se, provavelmente, ao efeito da incorporação de restos vegetais na camada arável, antes da instalação no sistema plantio direto, e também a formação de "falsos agregados" devido à compressão do solo pelo tráfego de máquinas. ALBUQUERQUE et al. (1994) relatam a variação temporal da estabilidade dos agregados em manejo do solo com apenas um ano de cultivo. Fica evidente que a estabilidade da estrutura pode variar temporariamente com processos físicos relacionados com o clima, com o crescimento de plantas, com o preparo do solo e com o tráfego de maquinaria agrícola.

Observando o tempo de adoção do sistema plantio direto, nota-se aumento significativo nos agregados de maior diâmetro ( $>2 \mathrm{~mm})$, na profundidade de $0-5 \mathrm{~cm}$, no PD1, PD4, PD5 e PD12, com valores de 37,9\%, 42,9\%, 65,3\% e 89,0\%, respectivamente, enquanto, no PC, foi de apenas 22,8\% (Tabela 2). Esses dados corroboram aqueles apresentados por DA ROS et al. (1996), ressaltando o efeito benéfico do sistema plantio direto, contribuindo para a manutenção da sustentabilidade do solo. CASTRO FILHO et al. (1998), em estudo em Latossolo Roxo com 14 anos de duração, no sistema plantio direto, observaram que o aumento do teor de carbono orgânico resultou em aumento no DMP pela diminuição dos agregados de menor diâmetro $(<0,25 \mathrm{~mm})$ e aumento de agregados de maior diâmetro.

Deve-se também atribuir a maior agregação nos tratamentos sob plantio direto ao efeito das diferentes sucessões e rotações nos tratamentos em estudo. Esse efeito ocorreu com maior intensidade nos tratamentos PD4 e PD5, que tiveram predominância da cultura do milho como cultura de verão e diferentes plantas de cobertura no inverno (aveia-preta, milheto e triticale). Maiores benefícios das gramíneas têm sido relatados em diversos trabalhos (CARPENEDO \& MIELNICZUK, 1990; SILVA \& MIELNICZUK, 1997a; SILVA \& MIELNICZUK, 1998; CUNHA et al., 2007; CALONEGO \& ROSOLEM, 2008; SALTON et al., 2008).

A maior desagregação no sistema convencional e menor no sistema plantio direto (Tabela 2), segundo TISDALL \& OADES (1982), devem-se ao fato de que, em solos cultivados, os agregados são expostos com frequência à desagregação física, devido às mudanças climáticas (processo de umedecimento e secagem), ou à ação de implementos agrícolas. Resultados da intensa utilização de equipamentos de preparo do solo, com maior desagregação e degradação física de solo foram observados por CARPENEDO \& MIELNICZUK (1990) e CAMPOS et al. (1999).

Os resultados obtidos sugerem que o preparo de solo no sistema convencional, por mais de 20 anos, fracionou os agregados maiores em unidades menores, causando modificações significativas com relação às características originais, sendo essas mais afetadas quanto maior a intensidade de preparo do solo, tornando-o mais suscetível à erosão. A classe predominante de agregados no PC foi a $<1 \mathrm{~mm}$ (Tabela 2). Resultados semelhantes de fracionamento de agregados foram encontrados 
em diversos trabalhos por REINERT et al. (1984), CARPENEDO \& MIELNICZUK (1990), CAMPOS et al. (1995), DA ROS et al. (1996) e BEUTLER et al. (2001).

Analisando a classe de tamanho de agregado com diâmetro $<1 \mathrm{~mm}$, observa-se, na profundidade de 0-5 cm, diminuição significativa da percentagem dos agregados com a adoção do sistema plantio direto, o que também foi observado por CASTRO FILHO et al. (1998).

Já no primeiro ano no sistema plantio direto, houve aumento de $66 \%$ na classe de agregados $>2 \mathrm{~mm}$ em relação ao convencional, na profundidade de $0-5 \mathrm{~cm}$, e nas demais áreas, os seguintes acréscimos: PD4 (88\%), PD5 (187\%), PD12 (291\%) e MN (333\%). Entretanto, na profundidade de 10-15 cm, o acréscimo na classe de agregados de diâmetro $>2 \mathrm{~mm}$ com o tempo de adoção no sistema plantio direto foi menor (Tabela 2).

Os valores da classe de agregados maiores que $2 \mathrm{~mm}$ apresentaram o mesmo comportamento do DMP, concordando com os resultados obtidos por LACERDA et al. (2005) e CALEGARI et al. (2006), que observaram a mesma tendência, mostrando que essa classe de agregados também pode ser utilizada para expressar a agregação do solo.

A redução na percentagem dos agregados $<2 \mathrm{~mm}$ em relação ao $\mathrm{PC}$, na profundidade de 0-5 cm, foi da seguinte ordem: PD1 (20\%), PD4 (26\%), PD5 (55\%), PD12 (86\%) e MN (98,3\%).

A relação entre DMP e carbono orgânico apresentou regressão linear crescente significativa (Figura 1), demonstrando a importância da matéria orgânica como agente de agregação das partículas do solo. Para os agregados maiores do que $2 \mathrm{~mm}$, o comportamento foi semelhante ao do DMP. Apesar dos baixos coeficientes de determinação para a relação entre o DMP $\left(\mathrm{R}^{2}=0,42\right)$ e para agregados $>2 \mathrm{~mm}$ e CO $\left(\mathrm{R}^{2}=0,41\right)$, esses foram significativos a $1 \%$, demonstrando a ação de outros agentes, além da matéria orgânica na agregação do solo. WENDLING et al. (2005), em estudo avaliando diferentes sistemas de manejo do solo, constataram elevados coeficientes de correlação entre carbono orgânico e DMP, e também entre agregados $>2 \mathrm{~mm}$. Segundo PALADINI \& MIELNICZUK (1991), a correlação positiva entre agregados maiores que $2 \mathrm{~mm}$ e carbono orgânico indica que os compostos orgânicos podem ter atuado na formação e na estabilização desses agregados, além de servirem de fonte de energia para a flora microbiana do solo, que são importantes agentes de agregação.

A relação entre o DMP dos agregados e os teores de carbono orgânico é demonstrada por diversos autores, tais como SILVA \& MIELNICZUK (1997b) e PERUSI \& CARVALHO (2007), que observaram que a importância da matéria orgânica na estabilidade dos agregados é variável com a textura e a mineralogia dos solos, entre outros fatores.

As classes de agregados entre 2-1 mm (D 2-1 mm) e agregados menores do que $1 \mathrm{~mm}$ $(\mathrm{D}<1 \mathrm{~mm})$ apresentaram relações lineares significativas e negativas com os teores de carbono orgânico (Figura 1). WOHLENBERG et al. (2004) constataram que o mecanismo dominante de agregação está relacionado com o carbono orgânico, e à medida que esse diminui, principalmente pelo preparo excessivo do solo ou baixo aporte de material orgânico pelos sistemas de cultivos, decresce a estabilidade dos agregados. 

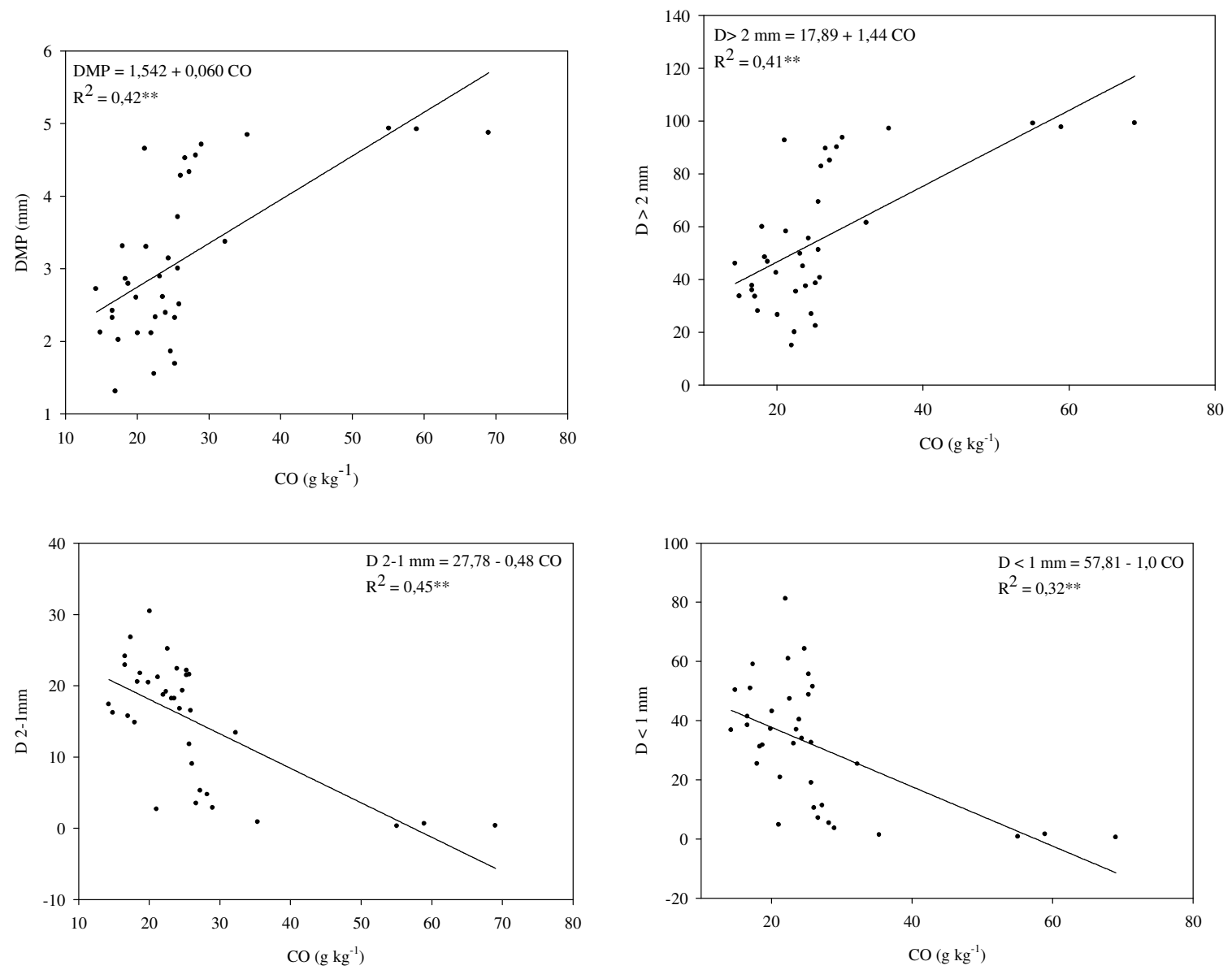

FIGURA 1. Relação entre o diâmetro médio ponderado (DMP), diâmetro de agregados maiores que $2 \mathrm{~mm}(\mathrm{D}>2 \mathrm{~mm})$, diâmetro de agregados entre 2-1 $\mathrm{mm}$ (D 2-1 mm), diâmetro de agregados menores que $1 \mathrm{~mm}(\mathrm{D}<1 \mathrm{~mm})$ e os teores de carbono orgânico (CO). ** Significativo a $1 \%$. Ratio between mean weighted diameter (MWD), diameter of aggregates larger than $2 \mathrm{~mm}(D>2 \mathrm{~mm})$, diameter of aggregates between 2-1 mm (D 2-1 mm), diameter of aggregates smaller than $1 \mathrm{~mm}(\mathrm{D}<1$ $\mathrm{mm}$ ), and organic carbon contents (OC). ** Significant at $1 \%$.

\section{CONCLUSÕES}

O tempo de adoção do sistema plantio direto favoreceu a agregação do solo.

O diâmetro médio ponderado (DMP) dos agregados do solo e a percentagem de agregados maiores do que $2 \mathrm{~mm}$ foram crescentes com o tempo de adoção no sistema plantio direto, na profundidade de $0-5 \mathrm{~cm}$.

A MN e o PD12 apresentaram maiores DMPs na profundidade de $0-5 \mathrm{~cm}$.

$\mathrm{O}$ PC apresentou maior percentual de agregados menores do que $1 \mathrm{~mm}$.

\section{REFERÊNCIAS}

ALBUQUERQUE, J.A.; REINERT, D.J.; FIORIN, J.E. Variação temporal da estabilidade estrutural em Podzólico Vermelho-Amarelo. Ciência Rural, Santa Maria, v.24, n.2, p.275-280, 1994. 
ANGERS, D.A. Changes in soil aggregation and organic carbon under corn and alfafa. Soil Science Society America Journal, Madison, v.56, n.4, p.1.244-1.249, 1992.

BAYER, C.; MIELNICZUK, J. Dinâmica e função da matéria orgânica. In: SANTOS, G.A.; CAMARGO, F.A.O. (Eds.) Fundamentos da matéria orgânica do solo: ecossistemas tropicais e subtropicais. Porto Alegre: Genesis, 1999. p.9-26.

BERTONI, J.; LOMBARDI NETO, F. Conservação do solo. São Paulo: Ícone, 1990. 355 p.

BEUTLER, A.N.; SILVA, M.L.N.; CURI, N.; FERREIRA, M.M.; PEREIRA FILHO, I.A.; CRUZ, J.C. Agregação de Latossolo Vermelho distrófico típico relacionada com o manejo na região dos cerrados no Estado de Minas Gerais. Revista Brasileira de Ciência do Solo, Viçosa, v.25, n.1, p.129-136, 2001.

CALEGARI, A.; CASTRO FILHO, C. de; TAVARES FILHO, J.; RALISCH, R.; GUIMARÃES, M. de F. Semina: Ciências Agrárias, Londrina, v.27, n. 2, p.147-158, 2006.

CALONEGO, J.C.; ROSOLEM, C.A. Estabilidade de agregados do solo após manejo com rotações de culturas e escarificação. Revista Brasileira de Ciência do Solo, Viçosa, v.32, n.4, p.1.399-1.407, 2008.

CAMPOS, B.C.; REINERT, D.J.; NICOLODI, R.; CASSOL, L.C. Dinâmica da agregação induzida pelo uso de plantas de inverno para cobertura do solo. Revista Brasileira de Ciência do Solo, Viçosa - MG, v.23, n.2, p.383-391, 1999.

CAMPOS, B.C. de; REINERT, D.J.; NICOLODI, R.; RUEDELL, J.; PETRERE, C. Estabilidade estrutural de um Latossolo Vermelho-Escuro distrófico após sete anos de rotação de culturas e sistemas de manejo de solo. Revista Brasileira de Ciência do Solo, Viçosa- MG, v.19, n.1, p.121$126,1995$.

CARPENEDO, V.; MIELNICZUK, J. Estado de agregação e qualidade de agregados de Latossolos Roxos, submetidos a diferentes sistemas de manejo. Revista Brasileira de Ciência do Solo, Viçosa MG, v.14, n.1, p.99-105, 1990.

CASTRO FILHO, C.; MUZILLI, O.; PODANOSCHI, A.L. Estabilidade dos agregados e sua relação com o teor de carbono orgânico num Latossolo Roxo distrófico, em função de sistemas de plantio, rotações de culturas e métodos de preparo das amostras. Revista Brasileira de Ciência do Solo, Viçosa - MG, v.22, n.3, p.527-538, 1998.

CUNHA, E. de Q.; BALBINO, L.C.; STONE, L.F.; LEANDRO, W.M.; OLIVEIRA, G.C. de. Influência de rotações de culturas nas propriedades físico-hídricas de um Latossolo Vermelho em plantio direto. Engenharia Agrícola, Jaboticabal, v.27, n.3, p.665-674, 2007.

DA ROS, C.O.; LOPES, C.E.L.; SECCO, D.; PASA, L. Influência do tempo de adoção no sistema de plantio direto nas características físicas de um Latossolo Vermelho-Escuro. In: REUNIÃO SUL-BRASILEIRA DE CIÊNCIA DO SOLO, 1., 1996, Lages. Resumos. Pelotas: Sociedade Brasileira de Ciência do Solo - Núcleo Regional Sul, 1996. p.153-155.

EMBRAPA. EMPRESA BRASILEIRA DE PESQUISA AGROPECUÁRIA. Centro Nacional de Pesquisa de Solos. Manual de métodos de análise de solo. 2.ed. Rio de Janeiro, 1997. 212 p.

HARRIS, R.F.; CHESTERS, G.; ALLEN, O.N. Dynamics of soil aggregation. Advances in Agronomy, New York, v.18, n.1, p.107-169, 1966.

KEMPER, W.D.; CHEPIL, W.S. Size distribuition of agregates. In: BLACK, C.A. (Ed.) Methods of soil analysis. Madison: American Society of Agronomy, 1965. part 1, p.499-510.

LACERDA, N.B.; ZERO, V.M.; BARILLI, J.; MORAES, M.H.; BICUDO, S.J. Efeito de sistemas de manejo na estabilidade de agregados em um Nitossolo Vermelho. Engenharia Agrícola, Jaboticabal, v.25, n.3, p.686-695, 2005. 
OLIVEIRA, G.C. de. Alterações estruturais e comportamento compressivo de um Latossolo submetido a diferentes sistemas de manejo por 20 anos no cerrado. 2002. $78 \mathrm{f}$. Tese (Doutorado em Solos e Nutrição de Plantas) - Universidade Federal de Lavras, Lavras, 2002.

PALADINI, F.L.S.; MIELNICZUK, J. Distribuição de tamanho de agregados de um solo Podzólico Vermelho-Escuro afetado por sistemas de culturas. Revista Brasileira de Ciência do Solo, Viçosa MG, v.15, n.2, p.135-140, 1991.

PERUSI, M.C.; CARVALHO, W.A. Avaliação da estabilidade de agregados de Argissolos em diferentes sistemas de uso e manejo no município de Anhumas - SP. Energia na Agricultura, Botucatu, v.22, n.1, p.94-111, 2007.

REINERT, D.J.; MUTTI, L.S.M.; ZAGO, A.; AZOLIN, M.A.D.; HOFFMANN, C.L. Efeito de diferentes métodos de preparo do solo sobre a estabilidade de agregados em solo Podzólico Vermelho-Amarelo. Ciência Rural, Santa Maria, v.14, n.1, p.19-25, 1984.

SALTON, J.C.; MIELNICZUK, J.; BAYER, C.; BOENI, M.; CONCEIÇÃO, P.C.; FABRÍCIO, A.C.; MACEDO, M.C.M.; BROCH, D.L. Agregação e estabilidade de agregados do solo em sistemas agropecuários em Mato Grosso do Sul. Revista Brasileira de Ciência do Solo, Viçosa, v.32, n.1, p.11-21, 2008.

SAS Institute. SAS language and prodecure: usage. Version 6. Cary, 1995. 373 p.

SILVA, I.F. da; MIELNICZUK, J. Ação do sistema radicular de plantas na formação e estabilização de agregados do solo. Revista Brasileira de Ciência do Solo, Viçosa, v.21, n.1, p.113117, 1997a.

SILVA, I.F. da; MIELNICZUK, J. Avaliação do estado de agregação do solo afetado pelo uso agrícola. Revista Brasileira de Ciência do Solo, Viçosa, v.21, n.2, p.313-319, $1997 \mathrm{~b}$.

SILVA, I.F.; MIELNICZUK, J. Sistemas de cultivo e características do solo afetando a estabilidade de agregados. Revista Brasileira de Ciência do Solo, Viçosa, v.22, n.2, p.311-317, 1998.

TISDALL, J.M.; OADES, J.M. Organic matter and water-stable aggregates in soils. Journal of Soil Science, London, v.33, n.1, p.141-163, 1982.

TISDALL, J.M.; OADES, J.M. Stabilization of soil aggregates by the root systems of ryegrass. Australian Journal of Soil Research, Collingwood, v.17, n.3, p.429-441, 1979.

WENDLING, B.; JUCKSCH, I.; MENDONÇA, E. de S.; NEVES, J.C.L. Carbono orgânico e estabilidade de agregados de um Latossolo Vermelho sob diferentes manejos. Pesquisa Agropecuária Brasileira, Brasília, v.40, n.5, p.487-494, 2005

WOHLENBERG, E.V.; REICHERT, J.M.; REINERT, D.J.; BLUME, E. Dinâmica da agregação de um solo franco-arenoso em cinco sistemas de culturas em rotação e em sucessão. Revista Brasileira de Ciência do Solo, Viçosa, v.28, n.5, p.891-900, 2004. 